\title{
Contrasting protist communities (Cercozoa: Rhizaria) in pristine and earthworm-invaded North American deciduous forests
}

\author{
Kenneth Dumack (D) Olga Ferlian • Deisy Morselli Gysi · Florine Degrune • \\ Robin-Tobias Jauss · Susanne Walden · Hüsna Öztoprak · Tesfaye Wubet • \\ Michael Bonkowski $\cdot$ Nico Eisenhauer
}

Received: 1 February 2021 / Accepted: 17 December 2021 / Published online: 5 January 2022

(C) The Author(s) 2022

\begin{abstract}
Earthworms are considered ecosystem engineers due to their fundamental impact on soil structure, soil processes and on other soil biota. An invasion of non-native earthworm species has altered soils of North America since European settlement, a process currently expanding into still earthworm-free forest ecosystems due to continuous spread and increasing soil temperatures owing to climate change. Although earthworms are known to modify soil microbial diversity and activity, it is as yet unclear
\end{abstract}

Supplementary Information The online version contains supplementary material available at https://doi.org/10.1007/ s10530-021-02726-x.

K. Dumack $(\bowtie) \cdot$ S. Walden · H. Öztoprak ·

M. Bonkowski

Terrestrial Ecology, Institute of Zoology, University of Cologne, Zülpicher Str. 47b, 50674 Cologne, Germany

e-mail: kenneth.dumack@uni-koeln.de

O. Ferlian · T. Wubet · N. Eisenhauer

German Centre for Integrative Biodiversity Research

(iDiv) Halle-Jena-Leipzig, Puschstr. 4, 04103 Leipzig,

Germany

O. Ferlian · N. Eisenhauer

Institute of Biology, Leipzig University, Puschstr. 4, 04103 Leipzig, Germany

D. Morselli Gysi

Network Science Institute and Department of Physics, Northeastern University, Boston, MA 02115, USA how eukaryote consumers in soil microbial food webs will be affected. Here, we investigated how earthworm invasion affects the diversity of Cercozoa, one of the most dominant protist taxa in soils. Although the composition of the native cercozoan community clearly shifted in response to earthworm invasion, the communities of the different forests showed distinct responses. We identified 39 operational taxonomic units (OTUs) exclusively indicating earthworm invasion, hinting at an earthworm-associated community of Cercozoa. In particular, Woronina pythii, a hyper-parasite of plant-parasitic Oomycota in American forests, increased strongly in the presence

\author{
D. Morselli Gysi \\ Channing Division of Network Medicine, Department of \\ Medicine, Brigham and Women's Hospital, Harvard \\ Medical School, Boston, MA 02115, USA \\ F. Degrune \\ Soil Science and Environment Group, CHANGINS, \\ University of Applied Sciences and Arts Western \\ Switzerland, Route de Duillier 50, 1260 Nyon, \\ Switzerland \\ R.-T. Jauss \\ Institute of Biology, Molecular Evolution \& Animal \\ Systematics, Talstraße 33, 04103 Leipzig, Germany \\ T. Wubet \\ Department of Community Ecology, UFZ-Helmholtz- \\ Centre for Environmental Research, Theodor-Lieser- \\ Straße 4, 06120 Halle (Saale), Germany
}


of invasive earthworms, indicating an influence of invasive earthworms on oomycete communities and potentially on forest health, which requires further research.

Keywords Biological invasion - Ecosystem engineer - Soil invertebrates - Soil microorganisms . Biodiversity change $\cdot$ Protists

\section{Introduction}

Large parts of North American temperate forests have been devoid of native earthworm species since the last glacial period (Hendrix and Bohlen 2002; Bohlen et al. 2004; Callaham et al. 2006; Frelich et al. 2019). Although a variety of non-native earthworm species have been repeatedly introduced since the arrival of European settlers, extensive areas of the northern regions still remained earthworm-free due to their severe climatic conditions with harsh winters (Callaham et al. 2006). The increase of winter soil temperatures in conjunction with the current climate change led to an invasion of native forest ecosystems at higher altitudes and higher latitudes by non-native earthworm species (Fisichelli et al. 2013). Moreover, manifold human activities facilitate the distribution and spread of non-native earthworms in northern North America (Holdsworth et al. 2007; Cameron et al. 2007).

Earthworms are known as ecosystem engineers which profoundly shape soil ecosystems (Knollenberg et al. 1985; Lavelle et al. 1997; Butenschön et al. 2009; Eisenhauer 2010). Earthworms process large amounts of plant litter by fragmentation and bioturbation, with major consequences for the cycling of carbon and nutrients in forest ecosystems (Scheu 1987, 1994; Scheu and Wolters 1991; Fahey et al. 2013). Earthworm burrow walls and casts, i.e. the drilosphere, are soil hotspots with increased availability of $\mathrm{C}$ and $\mathrm{N}$ (Brown 1995; Eisenhauer 2010) and with much higher microbial activity and abundance than surrounding soil (Maraun et al. 1999; Tiunov et al. 2001; Tao et al. 2009; Andriuzzi et al. 2016). Subsequent shifts of soil microbial food webs lead to an altered soil animal and microbial community and may even affect plant community composition (Eisenhauer et al. 2007; Nuzzo et al. 2009; Craven et al. 2017; Ferlian et al. 2018). However, despite evidence for significant shifts in soil biodiversity and community composition in response to earthworm invasion (Ferlian et al. 2018), there have been no studies on the fate of soil protists.

There are indications of a tight trophic relationship of earthworms with protists (i.e. unicellular eukaryotes) (Bonkowski and Schaefer 1997; Scheu and Setälä 2002). Thus, indirect effects of earthworms, via casting and burrowing, and direct impacts through consumption of protist communities are expected with potential ripple effects on other trophic levels (Bonkowski et al. 2001). Although soil protists have been predominantly considered as consumers of bacteria (Clarholm 1981, 1985; Glücksman et al. 2010; Trap et al. 2016; Flues et al. 2017), they are increasingly recognised as consumers of fungi in soil ecosystems (Geisen et al. 2015a; Dumack et al. 2016, 2018). Due to their high abundance, high turnover and assimilation rates, they occupy a key position for the energy transfer from microorganisms to higher trophic levels in forest soil food webs (Schaefer and Schauermann 1990; Schröter et al. 2003; Moore et al. 2005). Moreover, there is accumulating evidence for the significant role of plant parasitic protists to play crucial roles in many ecosystems (Delgado-Baquerizo et al. 2020; Hittorf et al. 2020).

Even with the rise of molecular methods in the assessment of microbial communities, the molecular assessment of protists remains difficult. Protists are polyphyletic and highly diverse; accordingly, there is no universal protocol to assess all protists. Primerbased metabarcoding is inevitably selective, as there is no general primer that enables the assessment of all protist groups (Lentendu et al. 2014; Hirakata et al. 2019). In addition, protists vary in their genome sizes and ribosomal copy numbers, which obscures results of metabarcoding surveys (Amend et al. 2010; Weber and Pawlowski 2013; Lentendu et al. 2014; Sibbald and Archibald 2017; Hirakata et al. 2019). However, despite these difficulties, there is a consensus that the protistan taxa Cercozoa and Amoebozoa represent the dominant protistan taxa in soil (Urich et al. 2008; Geisen et al. 2015b; Grossmann et al. 2016; Bonkowski et al. 2019) and forest litter (Voss et al. 2019). Specific metabarcoding protocols for the comprehensive assessment of the total diversity of one of these two taxa, the Cercozoa, have been developed (Bugge Harder et al. 2016; Fiore-Donno et al. 2018, 2019; Degrune et al. 2019). The Cercozoa comprise a vast 
variety of different morphotypes, including flagellates, amoeboflagellates, naked amoebae, and testate flagellates as well as amoebae with diverse functional roles, such as bacterivores, fungivores, eukaryvores, and omnivores or algivores (Seppey et al. 2017; Bonkowski et al. 2019; Dumack et al. 2019). This means that protists do not only have many important ecosystem effects, they can also serve as crucial bioindicators for soil community composition and health (Geisen et al. 2020).

Following the protocols published by Fiore-Donno et al. (2018), we assessed the effects of earthworm invasion on cercozoan communities of three North American boreal and temperate-boreal forests (in Minnesota, USA, and Alberta, Canada). These sites have been invaded by anecic (Lumbricus terrestris), endogeic (Octolasion tyrtaeum) and epigeic (Dendrobaena octaedra) earthworms (Frelich et al. 2006; Eisenhauer et al. 2007). We hypothesised that (1) earthworms affect the composition of cercozoan communities in soil, and (2) that bioturbation by earthworms homogenises cercozoan communities across the upper soil profile.

\section{Material and methods}

Study site

The study sites were chosen as they have been under investigation for two decades and accordingly show a gradient of differing abiotic or biotic conditions along the earthworm invasion history (Eisenhauer et al. 2019; Jochum et al. 2021; Supplementary Table 1).

The first study site is located in a boreal forest north of Barrier Lake in Kananaskis Valley in the Rocky Mountains, south west Alberta, Canada (hereafter called Barrier Lake North; $51^{\circ} 02^{\prime} \mathrm{N}, 115^{\circ} 03^{\prime} \mathrm{W}$ ). The site is at $1510 \mathrm{~m}$ a.s.l. on a slope facing south. The second study site is located south of Barrier Lake in Kananaskis Valley (hereafter called Barrier Lake South, $51^{\circ} 01^{\prime} \mathrm{N}, 115^{\circ} 04^{\prime} \mathrm{W}$ ) at $1380 \mathrm{~m}$ a.s.l. on a slope facing west about $2.8 \mathrm{~km}$ from the first site. Both sites are characterised by a continental climate with cold, long winters and dry, short summers. The soil is usually frozen between November and March. The mean annual precipitation and temperature are $638 \mathrm{~mm}$ and $3.4{ }^{\circ} \mathrm{C}$, respectively. The soil type is classified as Orthic Grey Luvisol. The soil of the first site has a $\mathrm{pH}$ of 6.1 and an organic layer thickness of about $7.3 \mathrm{~cm}$. The soil of the second site has a $\mathrm{pH}$ of 5.8 and an organic layer thickness of around $5.5 \mathrm{~cm}$. The tree communities of both sites are dominated by Populus balsamifera L. and Populus tremuloides Michx. interspersed with single Picea glauca (Moench) Voss. The understorey vegetation is dense, species-rich and dominated by Rosa L. and Aster L. species, Viola canadensis L., Epilobium angustifolium L. Holub, and Delphinium glaucum S.Watson. The sites have moving earthworm invasion fronts as documented before (e.g. Eisenhauer et al., 2007; Straube et al., 2009) and confirmed by earthworm sampling conducted on all plots of the present study. The part of each site uphill from the invasion front was designated as uninvaded area with no or only low biomass (single individuals) of epigeic, endogeic and anecic earthworm species (hereafter called uninvaded area), whereas the part of each site downhill from the invasion front was designated as invaded area, where biomasses of epigeic, endogeic, and anecic earthworm species were high (hereafter called invaded area).

The third study site is located in a temperate-boreal forest, part of the Saint John's University, $120 \mathrm{~km}$ north west of Minneapolis, Minnesota, USA (hereafter called Saint John's, $45^{\circ} 34^{\prime} \mathrm{N}, 94^{\circ} 23^{\prime} \mathrm{W}$ ). The site is flat at $350 \mathrm{~m}$ a.s.l. It is characterised by a humid continental, cold temperate climate. The mean annual precipitation and temperature are $701 \mathrm{~mm}$ and $6.2{ }^{\circ} \mathrm{C}$, respectively. The soil type is classified as Glossic Eutroboralf. The soil has a pH of 4.9 and an organic layer thickness of about $1.6 \mathrm{~cm}$. The tree community of the site is dominated by Acer saccharum Marshall. The understorey vegetation is sparse and dominated by Urtica dioica L., Carex pennsylvanica Lam., Amphicarpaea bracteata (L.) Fernald, and Eurybia macrophylla (L.) Cass. The uninvaded and invaded areas of the site are around $400 \mathrm{~m}$ apart separated by a small lake. Areas of earthworm presence and absence/ low biomasses were confirmed by earthworm sampling conducted on the plots of the present study.

\section{Sampling}

In August 2016, we set up 20 plots of $1 \times 1 \mathrm{~m}$ per forest site with an additional adjacent subplot of $0.3 \times 1 \mathrm{~m}$, ten in the uninvaded, ten in the invaded area, respectively. The plots were chosen randomly with a minimum distance between plots of $15 \mathrm{~m}$. We 
distributed ten plots in the uninvaded and ten plots in the invaded area without any pairing of plots. The distance between the closest invaded and uninvaded plots was around $400 \mathrm{~m}$ in Alberta, whereas the distance between the closest sites was roughly $3 \mathrm{~km}$. In Minnesota, the distance between uninvaded and invaded areas was roughly $2.5 \mathrm{~km}$. Each plot was separated into four quarters which were assigned to different sample types, such as vegetation, plant litter, soil invertebrate macrofauna, and bulk soil. Soil samples for DNA sequencing analysis were taken at a separate adjacent subplot outside the four quarters to avoid disturbance during sampling. Four soil cores with a diameter of $2 \mathrm{~cm}$ were taken per plot. All soil cores were subdivided into $0-5$ and $5-10 \mathrm{~cm}$ soil layers, homogenised per plot and soil layer using a 2-mm sieve, and transferred into $15 \mathrm{ml}$ tubes. Samples were stored on dry ice in the field and for transport and later at $-80{ }^{\circ} \mathrm{C}$ in the lab until further processing. All tools were washed and sterilised with ethanol before and between sampling.

\section{DNA Extraction}

Soil microbial genomic DNA was extracted from each of the soil samples using a PowerSoil DNA Isolation Kit (MO BIO Laboratories Inc., Carlsbad, CA, United States) according to the slightly modified manufacturer's instructions. We used $0.4 \mathrm{~g}$ instead of $0.25 \mathrm{~g}$ of soil for the extractions and eluted in $100 \mu \mathrm{l}$ of the elution buffer. DNA yields from each sample were checked with a NanoDrop ND-8000 spectrophotometer (Thermo Fisher Scientific, Dreieich, Germany), and the extracts were stored at $-20^{\circ} \mathrm{C}$ for further analysis. The extracted DNAs were diluted by the factor of ten for subsequent PCRs.

PCRs and sequence processing

PCRs were conducted in two steps. In the first PCR, the forward primers S616F_Cerco and S616F_Eocer were mixed in the proportions of $80 \%$ and $20 \%$, and used with the reverse primer S963R_Cerco (FioreDonno et al. 2018). One $\mu \mathrm{l}$ of ten times diluted DNA were used as a template for the first PCR and $1 \mu \mathrm{l}$ of the resulting amplicons were used as a template for a following semi-nested PCR. We employed the following final concentrations: Dream Taq polymerase (Thermo Fisher Scientific, Dreieich, Germany) 0.01 units, Thermo Scientific Dream Taq Green Buffer, dNTPs $0.2 \mathrm{mM}$ and primers $1 \mu \mathrm{M}$. The conditions were set to an initial denaturation step at $95{ }^{\circ} \mathrm{C}$ for $2 \mathrm{~min}, 24$ cycles at $95{ }^{\circ} \mathrm{C}$ for $30 \mathrm{~s}, 50{ }^{\circ} \mathrm{C}$ for $30 \mathrm{~s}$, $72{ }^{\circ} \mathrm{C}$ for $30 \mathrm{~s}$; and a final elongation step at $72{ }^{\circ} \mathrm{C}$ for $5 \mathrm{~min}$. The second PCR was conducted with barcoded primers (see Fiore-Donno et al. 2018, combinations used are given in Supplementary Table 2). All PCRs were conducted twice to reduce the possible artificial dominance of few amplicons by PCR competition, and then pooled.

A mock community with known species richness of diverse cultivated cercozoan taxa was run in parallel to assist the fine-tuning of the bioinformatics pipeline as described in Fiore-Donno et al. (2018). The amplicons were checked by electrophoresis and $25 \mu \mathrm{l}$ of each pooled PCR product were purified and normalised using SequalPrep Normalization Plate Kit (Invitrogen $\mathrm{GmbH}$, Karlsruhe, Germany). We then pooled the samples and the mock community and proceeded for a single library preparation. Library preparation and paired-end MiSeq sequencing with the MiSeqv3 $2 \times 300$ bp kit were carried out by the Cologne Center for Genomics (CCG).

Paired reads were assembled using MOTHUR v.3.9 (Schloss et al. 2009) allowing one difference in the primers, no difference in the barcodes, no ambiguities, no mismatches higher than three and removing assembled sequences with an overlap < $200 \mathrm{bp}$. Reads were sorted into samples according to the barcodes. The mock community functioned as an internal standard for the analyses and saturation was reached. We could retrieve the expected ten OTUs of the mock community at $97 \%$ similarity when deleting OTUs represented by $<1000$ sequences, which equals a relative abundance of less than $3.5 \%$, and set this as a cutoff threshold for OTU delineation (see FioreDonno et al. 2018). The quality check and removal/cutting of low-quality reads were conducted with the default parameters. Using BLAST + with an e-value of $1 \mathrm{e}^{-50}$ and keeping only the best hit, sequences were identified a self-updated version of the PR2 database and non-cercozoan sequences were removed (Guillou et al. 2013). Chimeras were identified using UCHIME as implemented in MOTHUR with a penalty for opening gaps of -5 and a template for aligning operational taxonomic units. Sequences were clustered using VSEARCH v.1, with abundancebased greedy clustering (agc) and a similarity 
threshold of $97 \%$ as indicated by analysing the mock community. Sequencing data of the protists were deposited at the European Nucleotide Archive under the accession number ERS2039495 (SAMEA104421553).

\section{Statistical analysis}

All statistical analyses and data visualizations were conducted in $\mathrm{R}$ version 3.5.2 with the vegan package (Oksanen et al. 2014). Based on the obtained sequence reads for each OTU, we calculated the Chao1 index as a measure of OTU richness, evenness, Shannon index as a measure of alpha diversity, and Bray-Curtis dissimilarities for beta diversity. Nested Permutational Multivariate Analysis of Variance (Permanova) was employed to test for differences in Cercozoa community composition across treatments. The herein-defined treatments were thus (A) the earthworm invasion, which was treated as a factor with two levels and the strata (B) sampling site (forest) and (C) soil depth. The site effect explained most of the variation in the dataset. To cope with the large influence of the site, we computed a partial dbRDA with the capscale function to partial out the site effect. An indicative value analysis (Dufrêne and Legendre 1997) was performed with the indicspecies package (De Cáceres and Legendre 2009) to identify indicator taxa in the respective treatments. The taxonomic network was made with the igraph package and based on the taxonomic assignment inferred from the PR2 database and the therein used hierarchy (Csardi and Nepusz 2006; Guillou et al. 2013). The code for the statistical analysis is available online on Github (https://github.com/Kenneth-Dumack/Ecoworm).

\section{Results}

We obtained in total 555 cercozoan OTUs from initially $8,748,548$ sequences of 120 samples (3 forests $\times 2$ invasion status $\times 2$ soil depths $\times 10$ replicates; Fig. 1; Supplementary Table 3). Overall, the bacterivorous Sarcomonadea were the most diverse and most abundant taxon in this study. They represented about $45 \%$ of all OTUs (Fig. 1), with five OTUs ranking among the ten most frequently sequenced OTUs. The second most abundant OTU was Rhogostoma cylindrica, an omnivorous amoeba species. Moreover, we found a notably high number of sequence reads assigned to the bacterivorous Thaumatomonas (third most abundant OTU) and Spongomonadidae (eighth-most abundant OTU), and the oomycete hyperparasite Woronina pythii (ninth most abundant OTU).

Among the three forest sites, differences in cercozoan communities in terms of evenness, alpha and beta diversity could be detected (Permanova, richness: $\mathrm{df}_{[2,108]}, \mathrm{F}=6.46, \mathrm{p}=0.1343$, evenness: $\mathrm{df}_{[2,108]}$, $\mathrm{F}=5.523, \mathrm{p}=0.0012$, alpha diversity: $\left.\mathrm{df}_{[2,}, 108\right]$, $\mathrm{F}=1.95, \quad \mathrm{p}=0.0007$, beta diversity: $\left.\mathrm{df}_{[2,}, 108\right]$, $F=12.65, p=0.0001$; Fig. 2). However, the differences in the three measures were mostly due to the distinctness of Saint John's in comparison to Barrier Lake North and South (Fig. 2). In contrast to both Barrier Lake sites, Saint John's exhibited a high difference in alpha diversity and evenness between soil layers (Fig. 2). In general, the the sampling site affected the diversity indices (alpha diversity, evenness, and beta diversity, see Supplementary Table 4). Although all three sampling sites accommodated the same taxa with no difference in richness $\left(\mathrm{df}_{[2,}, 108\right]$, $\mathrm{F}=6.46, \mathrm{p}=0.13$ ), the taxa responded differently to changes in soil depth and earthworm invasion, which is shown by the numerous significant interactions between these to treatments. For instance, there was a significant interaction between site and soil depth for alpha and beta diversity as well as evenness (Permanova, richness: $\mathrm{df}_{[2,108]}, \mathrm{F}=1.21, \mathrm{p}=0.2952$, evenness: $\mathrm{df}_{[2,108]}, \mathrm{F}=5.09, \mathrm{p}=0.0078$, alpha diversity: $\mathrm{df}_{[2,108]}, \mathrm{F}=5.31, \mathrm{p}=0.0044$, beta diversity: $\mathrm{df}_{[2,108]}, \mathrm{F}=1.91, \mathrm{p}=0.0002$; Supplementary Table 4).

Earthworm invasion caused changes in the community composition of Cercozoa (Figs. 3, 4; Supplementary Fig. 1). When considering earthworm invasion on all three sites together, OTU richness, evenness and alpha diversity were not affected (Permanova, richness: $\mathrm{df}_{[2,108]}, \mathrm{F}=0.03, \mathrm{p}=0.8747$, evenness: $\mathrm{df}_{[2,108]}, \mathrm{F}=0.74, \mathrm{p}=0.3952$, alpha diversity: $\mathrm{df}_{[2,108]}, \mathrm{F}=1.06, \mathrm{p}=0.3103$; Fig. 4; Supplementary Table 4). However, there was a significant interaction between earthworm invasion and site on evenness, alpha and beta diversity, showing that the different sites showed contrasting responses on earthworm invasion (Permanova, richness: $\mathrm{df}_{[2,} \mathrm{1}_{108]}, \mathrm{F}=2.95, \mathrm{p}=0.0599$, evenness: $\left.\mathrm{df}_{[2,} 108\right], \quad \mathrm{F}=5.15, \mathrm{p}=0.0080$, alpha diversity: 


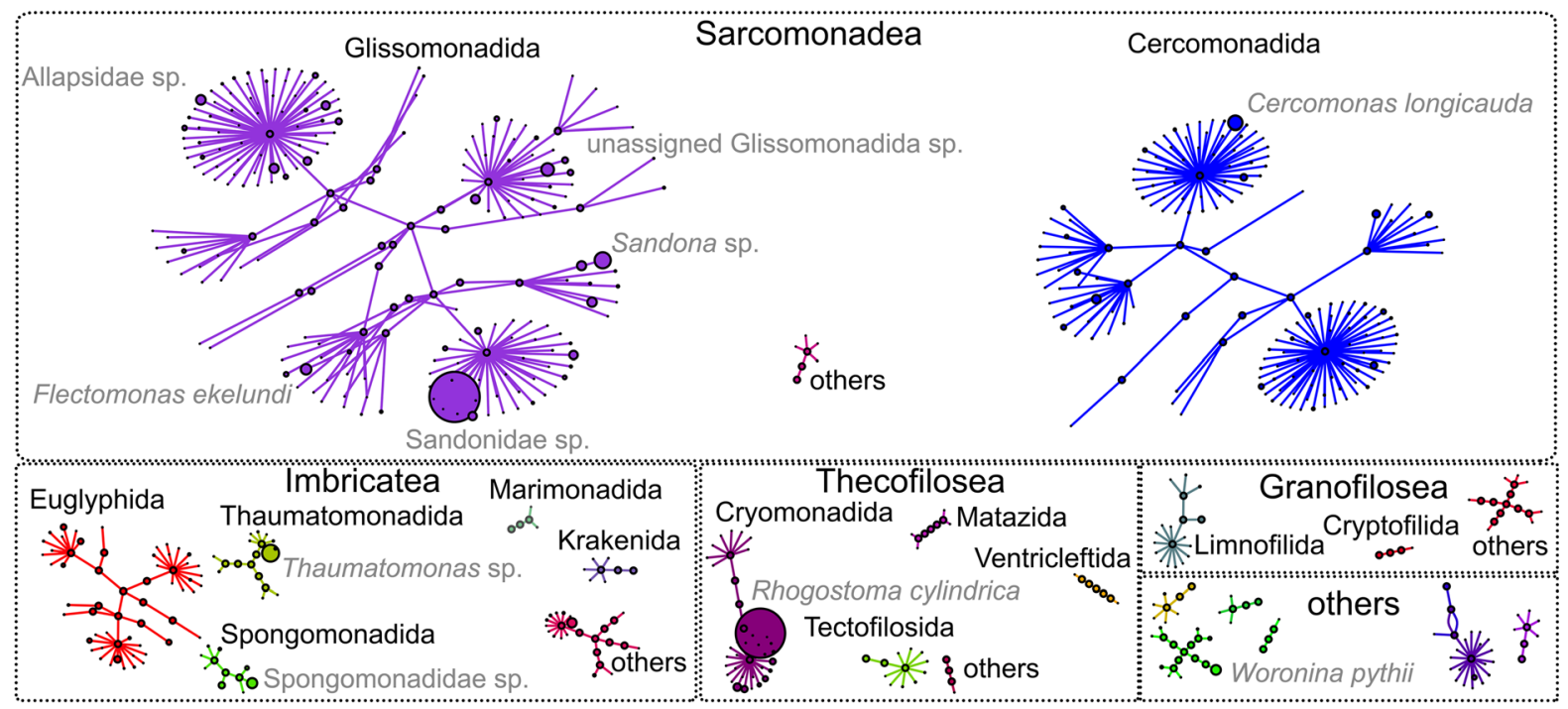

Fig. 1 Taxonomy-based network-like presentation of the diversity of Cercozoa in North American forest soils. Terminal nodes correspond to OTUs, and their respective size corresponds to the relative abundance of sequence reads in the

$\left.\mathrm{df}_{[2,} \quad 108\right], \quad \mathrm{F}=4.31, \quad \mathrm{p}=0.0137$, beta diversity: $\mathrm{df}_{[2,108]}, \mathrm{F}=3.84, \mathrm{p}=0.0001$; Fig. 1; Supplementary Table 4). For instance, earthworm invasion led to a decrease of alpha diversity and evenness in Barrier lake north, but not in Barrier lake south (Fig. 2).

Alpha and beta diversity of cercozoan communities were further affected by soil depth (Permanova, richness: $\mathrm{df}_{[2,108]}, \mathrm{F}=0.33, \mathrm{p}=0.5701$, evenness: $\left.\mathrm{df}_{[2,} 108\right], \quad \mathrm{F}=3.12, \mathrm{p}=0.0819$, alpha diversity: $\left.\mathrm{df}_{[2,}, 108\right], \quad \mathrm{F}=4.94, \quad \mathrm{p}=0.0259$, beta diversity: $\left.\mathrm{df}_{[2,108]}, \mathrm{F}=7.36, \mathrm{p}=0.0001\right)$ and there was a significant interaction between earthworm invasion and soil depth for beta diversity, but not for the other diversity indices (Permanova, richness: $\left.\mathrm{df}_{[2,}, 108\right]$, $\mathrm{F}=0.83, \mathrm{p}=0.3577$, evenness: $\mathrm{df}_{[2,108]}, \mathrm{F}=2.93$, $\mathrm{p}=0.0911$, alpha diversity: $\mathrm{df}_{[2,108]}, \mathrm{F}=3.01$, $\mathrm{p}=0.0831$, beta diversity: $\left.\mathrm{df}_{[2,}, 108\right], \quad \mathrm{F}=1.47$, $\mathrm{p}=0.0310$; Figs. 2,3).

The comparison of the influence of the treatments on cercozoan OTUs showed that in total 124 taxa were indicative for earthworm invaded soils, whereas 76 taxa indicated uninvaded soils. However, when taking into account the other treatments (site and depth), there were 39 taxa that exclusively indicated earthworm invasion (Supplementary Table 4). Interestingly, the abundance of Woronina pythii was dependent on earthworm invasion, showing a dataset. Edges represent the taxonomic ranks from order to OTU level. The ten most abundant OTUs are labelled in grey according to their closest hit in the PR2 database

significantly higher relative abundance, with a mean increase about 20 times, in earthworm-invaded sites (Supplementary Fig. 3).

\section{Discussion}

Earthworms affect soil microbial biomass and protist abundance directly via feeding (Bonkowski and Schaefer 1997) and indirectly via bioturbation, casting and burrowing (Maraun et al. 1999; Tiunov et al. 2001; Bonkowski et al. 2001; Tao et al. 2009). More recently, Andriuzzi et al. (2016) reported an altered community composition of protists in earthworm burrows. We investigated and compared how earthworm invasion affects cercozoan communities in northern North American forest soils.

Cercozoan communities differ among forests

The cercozoan communities of the three investigated sites were vastly different, and accordingly, cercozoan communities responded also differently to earthworm invasion. Differences in the cercozoan communities of our sampling sites, and thus also in response to earthworm invasion, may be explained by different biotic and abiotic conditions. Barrier Lake North and 
Fig. 2 Chaol richness, Shannon alpha diversity, and Sheldon evenness of cercozoan OTUs in earthworm invaded forests in Northern American are shown

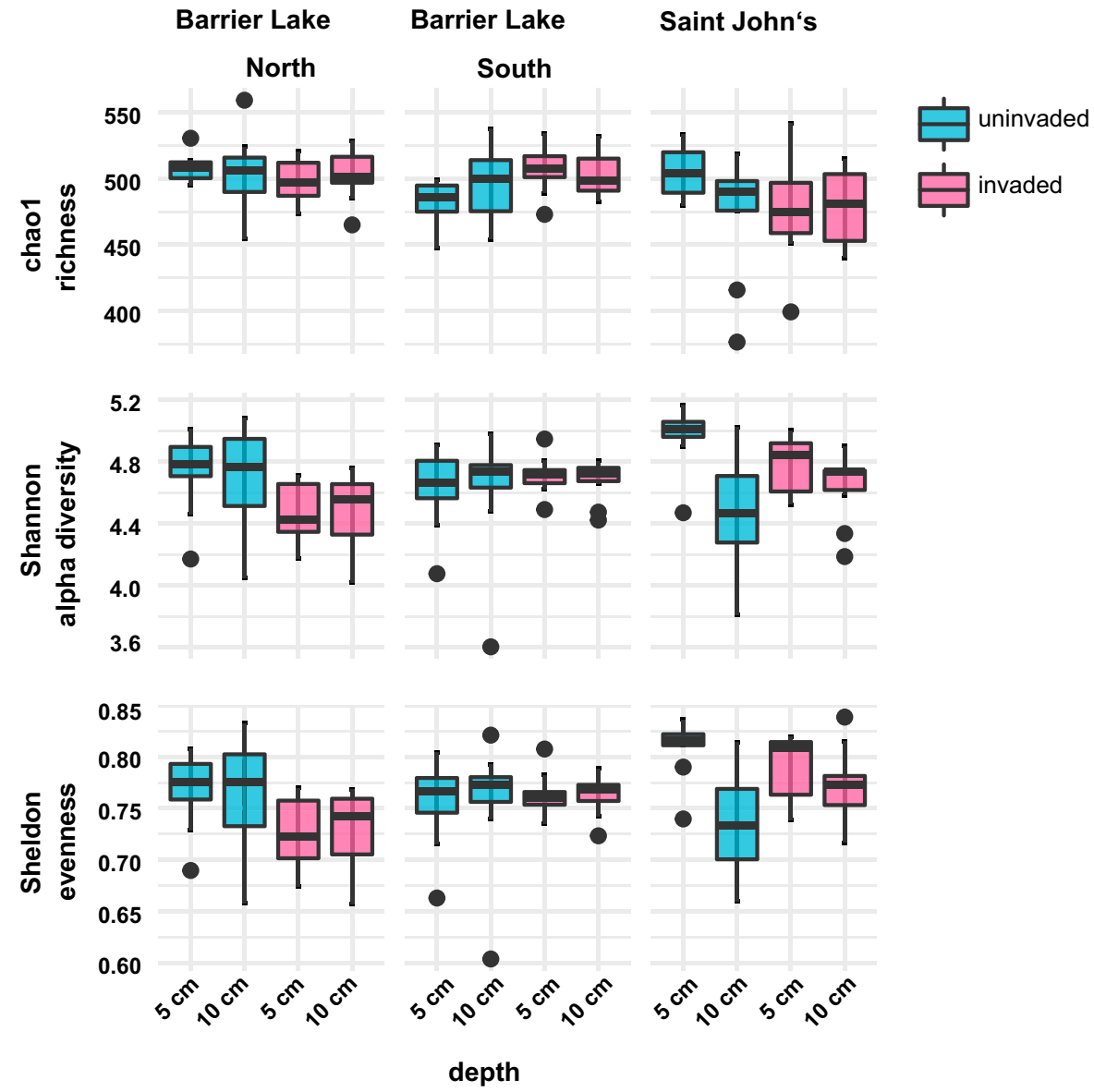

South were dominated by poplar trees and shared a similar soil type, while soil type and tree species differed profoundly in Saint John's maple forest. Fiore-Donno et al. (2020) could assign differences in cercozoan communities to both, differences between forest tree species and soil types, but could not disentangle both factors, because specific forest tree species occurred on distinct soils types. Accordingly, the differences in tree species and soil type of Barrier Lake North and South and Saint John's most likely explain the strong differences between cercozoan communities between the sampling sites. Moreover, the two Barrier Lake forests and the Saint John's forest also considerably differed in other soil abiotic properties. The former two had comparably higher soil water content, carbon and nitrogen concentrations, and thickness of the humus layer (Jochum et al. 2021). The understory vegetation was more developed and comprised different species in the Barrier Lake forests compared to Saint John's forest. And in addition, the forests may have differed in their invasion stage and, thus, in the proportions of earthworm ecological groups that are known to differently affect soil biota (Ferlian et al. 2018). Biotic and abiotic factors were shown to have strong effects on the community composition of protists (Tedersoo et al. 2016; de Araujo et al. 2018) and likely contribute to patterns of spatial separation in protist communities over large geographic distances (Venter et al. 2017; Singer et al. 2018, 2019). These general differences in cercozoan communities across forests likely explain their dissimilar responses to earthworm invasion.

Cercozoan communities are not uniformly altered by earthworm invasion

The cercozoan community composition changed with earthworm invasion. Although the present species were similar in all three forest sites the changes induced or accompanied by earthworm invasion were 
Fig. 3 Distance-based redundancy analaysis (dbRDA) of beta diversity of Cercozoa under earthworm invasion in North American forests

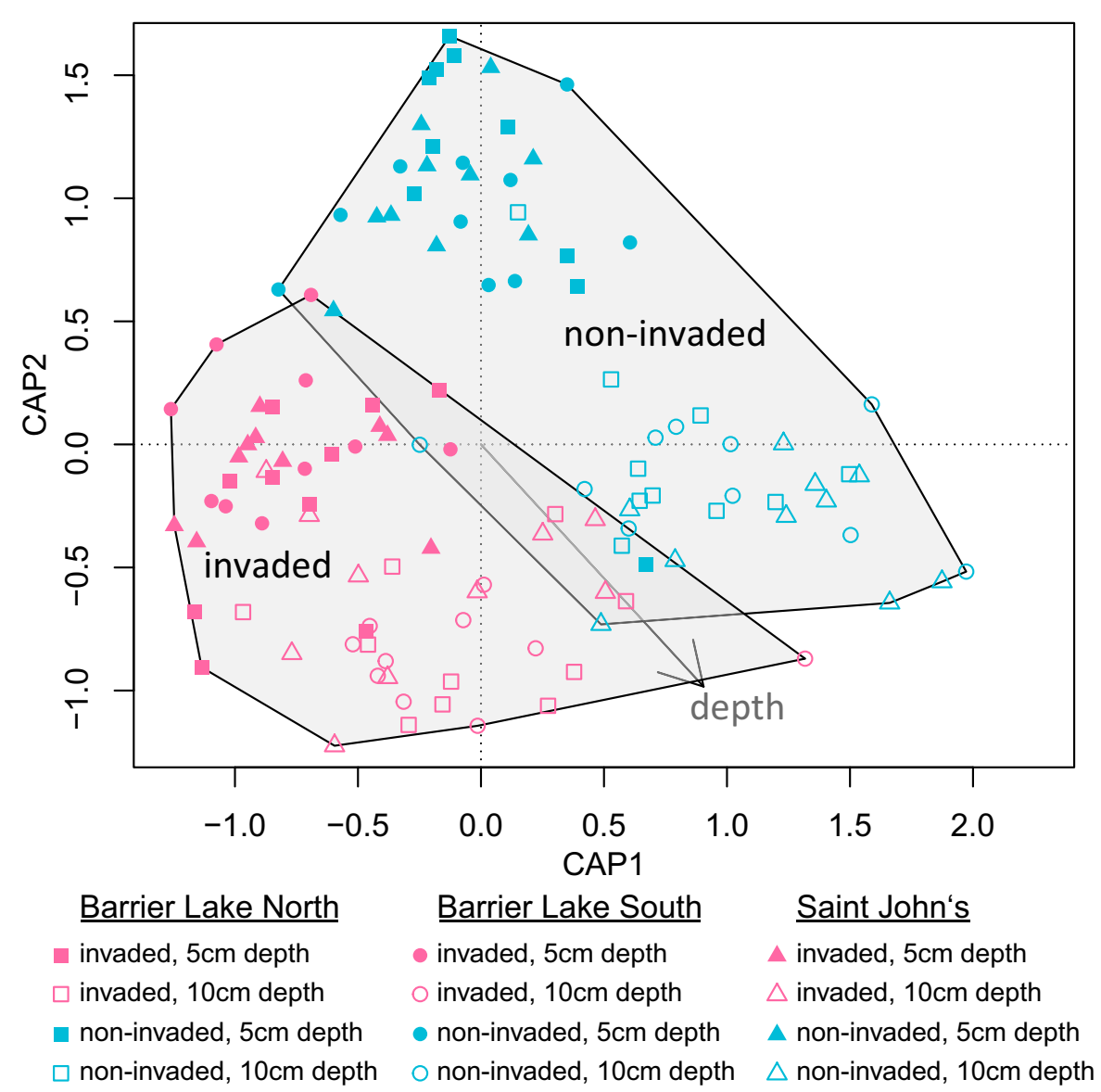

not similar, which was shown by the numerous interaction effects in our statistical analysis. A reasonable interpretation for the observed patterns is therefore that earthworms and an interplay of environmental and potentially other biotic interactions affect the cercozoan community. Even the quite similar sampling sites, like Barrier Lake North and Barrier Lake South, showed contrasting results. For instance, Barrier Lake South shows no changes in alpha diversity and evenness, although Barrier Lake North does show a decrease in both (Fig. 2). We conclude that the complexity of how soil microbial communities are affected needs further investigation taking other groups of soil microorganisms into account.
Earthworm invasion alters protist communities and potential consequences for plant communities

Sarcomonadea and an OTU assigned to Rhogostoma cylindrica (Thecofilosea) generally dominated the cercozoan communities, despite strong differences of community composition between Saint John's and Barrier Lake North and South. These taxa are common to be diverse and abundant in soil (Dumack et al. 2017; Fiore-Donno et al. 2018, 2019; Degrune et al. 2019; Jauss et al. 2020; Öztoprak et al. 2020). However, the high abundance of OTUs, which were assigned to Thaumatomonas, Spongomonadidae and Woronina pythii was unexpected, since they occur only rarely or were found to be entirely absent in forests (FioreDonno et al., 2020; Voss et al., 2019; Fig. 1).

We found a number of indicator taxa for earthworm invasion (Fig. 4; Supplementary Table 5). Among the 124 taxa that indicated earthworm invasion 39 taxa did not indicate any other treatment. Among those were 


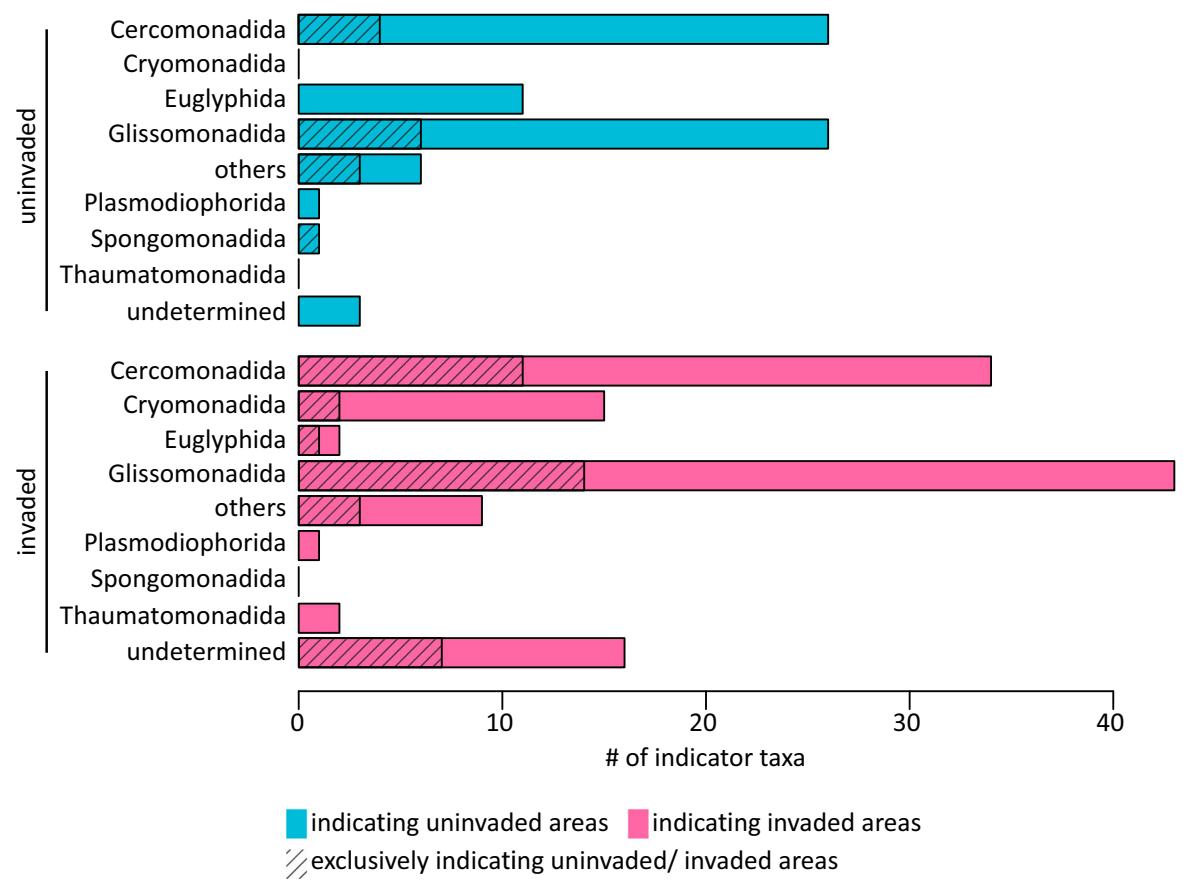

Fig. 4 The number of indicative taxa for uninvaded and invaded areas is shown. Cercozoan OTUs are ordered alphabetically and grouped by orders. The hatched area shows the

numerous OTUs referring to small bacterivorous flagellates of the Cercomonadida and Glissomonadida that might profit from earthworm invasion by increased dispersal or increased availability of carbon compounds. Interestingly a surprisingly high number (seven) of undetermined OTUs was found among the indicator taxa for earthworm invasion. Cercozoan OTUs that can not even be assigned to an order are common but usually lowly abundant and it might be presumed that especially these OTUs found here have not yet been characterized in the recent years of taxonomic revisions of Cercozoa as they might be a part of the earthworm microbiome that needs further investigation. However, it has to be mentioned that relationships found in an observational study are only correlative, and we cannot entirely rule out that the specific biotic and abiotic environment may have driven the distribution of earthworms. To keep such effects at a minimum, we investigated forests that have been studied for almost three decades using transect sampling methods that allow for a small-scale localization of invasion fronts as well as identification of potential dynamics of invasion fronts (Scheu 1994; Straube et al. 2009; Schlaghamerský et al. 2014; taxa that exclusively indicate earthworm invasion, i.e. are independent of other variables like sampling site and soil depth

Eisenhauer et al. 2019). This is further supported by two recent meta-analyses investigating the effects of earthworm invasion on soil biotic and abiotic parameters, respectively (involving the present forests as well; Ferlian et al. 2018, 2020). Both studies analysed the influence of study type and found marginal differences between lab and (observational and experimental) field studies, indeed suggesting an effect of earthworms on soil biotic and abiotic parameters.

Especially noteworthy is the high number of sequence reads assigned to $W$. pythii in our data set. Fiore-Donno et al. (2020) did not find this species in any of 150 German forest sites, while W. pythii was quite abundant in nearby grasslands. In the present study, we found it to occur in very low abundance in uninvaded sites, but with strongly increased relative abundance in invaded sites. W. pythii is a hyperparasite of ooymcetes, which are among the most devastating tree pathogens on the American continent (Jung et al. 2005; Garbelotto and Hayden 2012; Vargas and Negron-Ortiz 2013; Guajardo et al. 2019). The increase of $W$. pythii with earthworm invasion most likely provides indirect evidence of an enhanced oomycete abundance associated with earthworm 
invasion, which certainly deserves further scientific attention. Future studies should investigate if the present finding is a common phenomenon across different forests in northern North America that get invaded by earthworms and study the soil community (soil feedback) effects on plant performance and community composition.

Acknowledgements The authors are grateful to the anonymous reviewers for their thorough and constructive comments to this manuscript.

Funding Open Access funding enabled and organized by Projekt DEAL. This work was supported by the European Research Council (ERC) under the European Union's Horizon 2020 research and innovation program (Grant Agreement No. 677232 to N.E.). N.E. and O.F. also gratefully acknowledge the support of iDiv funded by the German Research Foundation (DFG-FZT 118, 202548816).

Data availability Sequencing data of the protists were deposited at the European Nucleotide Archive under the accession number ERS2039495 (SAMEA104421553).

Code availability The code for the statistical analysis is available online on Github (https://github.com/KennethDumack).

\section{Declarations}

Conflict of interest Not applicable.

Open Access This article is licensed under a Creative Commons Attribution 4.0 International License, which permits use, sharing, adaptation, distribution and reproduction in any medium or format, as long as you give appropriate credit to the original author(s) and the source, provide a link to the Creative Commons licence, and indicate if changes were made. The images or other third party material in this article are included in the article's Creative Commons licence, unless indicated otherwise in a credit line to the material. If material is not included in the article's Creative Commons licence and your intended use is not permitted by statutory regulation or exceeds the permitted use, you will need to obtain permission directly from the copyright holder. To view a copy of this licence, visit http://creativecommons.org/licenses/by/4.0/.

\section{References}

Amend AS, Seifert KA, Bruns TD (2010) Quantifying microbial communities with 454 pyrosequencing: does read abundance count? Mol Ecol 19:5555-5565. https://doi.org/10. 1111/j.1365-294X.2010.04898.x

Andriuzzi WS, Ngo P-TT, Geisen S et al (2016) Organic matter composition and the protist and nematode communities around anecic earthworm burrows. Biol Fertil Soils 52:91-100. https://doi.org/10.1007/s00374-015-1056-6

Bohlen PJ, Scheu S, Hale CM et al (2004) Non-native invasive earthworms as agents of change in northern temperate forests In a nutshell. Front Ecol Environ 2(8):427-435

Bonkowski M, Dumack K, Fiore-Donno AM (2019) The protists in soil: a token of untold eukaryotic diversity. In: van Elsas JD, Trevors JT, Rosado AS, Nannipieri P (eds) Modern soil microbiology. CRC Press, Boca Raton

Bonkowski M, Geoghegan IE, Birch ANE, Griffiths BS (2001) Effects of soil decomposer invertebrates (protozoa and earthworms) on an above-ground phytophagous insect (cereal aphid) mediated through changes in the host plant. Oikos 95:441-450. https://doi.org/10.1034/j.1600-0706. 2001.950309.x

Bonkowski M, Schaefer M (1997) Interactions between earthworms and soil protozoa: a trophic component in the soil food web. Soil Biol Biochem 29:499-502. https://doi.org/ 10.1016/S0038-0717(96)00107-1

Brown GG (1995) How do earthworms affect microfloral and faunal community diversity? Plant Soil 170:209-231. https://doi.org/10.1007/BF02183068

Bugge Harder C, Rønn R, Brejnrod A et al (2016) Local diversity of heathland Cercozoa explored by in-depth sequencing Local diversity of heathland Cercozoa explored by in-depth sequencing. ISME J 10:2488-2497. https://doi.org/10.1038/ismej.2016.31

Butenschön O, Marhan S, Langel R, Scheu S (2009) Carbon and nitrogen mobilisation by earthworms of different functional groups as affected by soil sand content. Pedobiologia (jena) 52:263-272. https://doi.org/10.1016/j.pedobi.2008. 11.001

Callaham MA, González G, Hale CM, et al (2006) Policy and management responses to earthworm invasions in North America. In: Biological Invasions. Springer, pp 1317-1329

Cameron EK, Bayne EM, Clapperton MJ (2007) Human-facilitated invasion of exotic earthworms into northern boreal forests. Ecoscience 14:482-490. https://doi.org/10.2980/ $1195-6860$

Clarholm M (1981) Protozoan grazing of bacteria in soil impact and importance. Microb Ecol 7:343-350

Clarholm M (1985) Interactions of bacteria protozoa and plants leading to mineralization of soil nitrogen. Soil Biol Biochem 17:181-187

Craven D, Thakur MP, Cameron EK et al (2017) The unseen invaders: introduced earthworms as drivers of change in plant communities in North American forests (a metaanalysis). Glob Chang Biol 23:1065-1074. https://doi.org/ $10.1111 /$ gcb. 13446

Csardi G, Nepusz T (2006) The igraph software package for complex network research. InterJournal Complex 1695:1-9

de Araujo ASF, Mendes LW, Lemos LN et al (2018) Protist species richness and soil microbiome complexity increase towards climax vegetation in the Brazilian Cerrado. Commun Biol 1:1-8. https://doi.org/10.1038/s42003-0180129-0

De Cáceres M, Legendre P (2009) Associations between species and groups of sites: indices and statistical inference. Ecology 90:3566-3574 
Degrune F, Dumack K, Fiore-Donno AM, Bonkowski M (2019) Distinct communities of Cercozoa at different soil depths in a temperate agricultural field. FEMS Microbiol Ecol 95:41. https://doi.org/10.1093/femsec/fiz041

Delgado-Baquerizo M, Reich PB, Trivedi C et al (2020) Multiple elements of soil biodiversity drive ecosystem functions across biomes. Nat Ecol Evol 4:210-220. https://doi. org/10.1038/s41559-019-1084-y

Dufrêne M, Legendre P (1997) Species assemblages and indicator species: the need for a flexible asymmetrical approach. Ecol Monogr 67:345-366

Dumack K, Fiore-Donno AM, Bass D, Bonkowski M (2019) Making sense of environmental sequencing data: ecologically important functional traits of the protistan groups Cercozoa and Endomyxa (Rhizaria). Mol Ecol Resour 20:398-403. https://doi.org/10.1111/1755-0998.13112

Dumack K, Flues S, Hermanns K, Bonkowski M (2017) Rhogostomidae (Cercozoa) from soils, roots and plant leaves (Arabidopsis thaliana): description of Rhogostoma epiphylla sp. nov. and $R$. cylindrica sp. nov. Eur J Protistol 60:76-86. https://doi.org/10.1016/j.ejop.2017.06.001

Dumack K, Müller M, Bonkowski M (2016) Description of Lecythium terrestris sp. nov. (Chlamydophryidae, Cercozoa), a soil dwelling protist feeding on fungi and algae. Protist 572:51-58. https://doi.org/10.1016/j.protis.2016. 01.001

Dumack K, Pundt J, Bonkowski M (2018) Food choice experiments indicate selective fungivorous predation in Fisculla terrestris (Thecofilosea, Cercozoa). J Eukaryot Microbiol 66:525-527. https://doi.org/10.1111/jeu.12680

Eisenhauer N (2010) The action of an animal ecosystem engineer: identification of the main mechanisms of earthworm impacts on soil microarthropods. Pedobiologia (jena) 53:343-352. https://doi.org/10.1016/j.pedobi.2010.04.003

Eisenhauer N, Ferlian O, Craven D et al (2019) Ecosystem responses to exotic earthworm invasion in northern North American forests. Res Ideas Outcomes. https://doi.org/10. 3897/rio.5.e34564

Eisenhauer N, Partsch S, Parkinson D, Scheu S (2007) Invasion of a deciduous forest by earthworms: changes in soil chemistry, microflora, microarthropods and vegetation. Soil Biol Biochem 39:1099-1110. https://doi.org/10.1016/ j.soilbio.2006.12.019

Fahey TJ, Yavitt JB, Sherman RE et al (2013) Earthworm effects on the incorporation of litter $\mathrm{C}$ and $\mathrm{N}$ into soil organic matter in a sugar maple forest. Ecol Appl 23:1185-1201. https://doi.org/10.1890/12-1760.1

Ferlian O, Eisenhauer N, Aguirrebengoa M et al (2018) Invasive earthworms erode soil biodiversity: a meta-analysis. J Anim Ecol 87:162-172. https://doi.org/10.1111/13652656.12746

Ferlian O, Thakur MP, Castañeda González A et al (2020) Soil chemistry turned upside down: a meta-analysis of invasive earthworm effects on soil chemical properties. Ecology 101:1-12. https://doi.org/10.1002/ecy.2936

Fiore-Donno AM, Richter-Heitmann T, Bonkowski M (2020) Contrasting responses of protistan plant parasites and phagotrophs to ecosystems, land management and soil properties. Front Microbiol 11:1-13. https://doi.org/10. 3389/fmicb.2020.01823
Fiore-Donno AM, Richter-Heitmann T, Degrune F et al (2019) Functional traits and spatio-temporal structure of a major group of soil protists (Rhizaria: Cercozoa ) in a temperate grassland. Front Microbiol 10:1-12. https://doi.org/10. 3389/fmicb.2019.01332

Fiore-Donno AM, Rixen C, Rippin M et al (2018) New barcoded primers for efficient retrieval of cercozoan sequences in high-throughput environmental diversity surveys, with emphasis on worldwide biological soil crusts. Mol Ecol Resour 18:229-239. https://doi.org/10.1111/1755-0998. 12729

Fisichelli NA, Frelich LE, Reich PB, Eisenhauer N (2013) Linking direct and indirect pathways mediating earthworms, deer, and understory composition in Great Lakes forests. Biol Invasions 15:1057-1066. https://doi.org/10. 1007/s10530-012-0350-6

Flues S, Bass D, Bonkowski M (2017) Grazing of leaf-associated Cercomonads (Protists: Rhizaria: Cercozoa) structures bacterial community composition and function. Environ Microbiol 19:3297-3309. https://doi.org/10.1111/14622920.13824

Frelich LE, Blossey B, Cameron EK et al (2019) Side-swiped: ecological cascades emanating from earthworm invasions. Front Ecol Environ 17:502-510. https://doi.org/10.1002/ fee. 2099

Frelich LE, Hale CM, Reich PB, et al (2006) Earthworm invasion into previously earthworm-free temperate and boreal forests. In: Biological invasions belowground: earthworms as invasive species. Springer pp 35-45

Garbelotto M, Hayden KJ (2012) Sudden oak death: interactions of the exotic oomycete phytophthora ramorum with naïve North American hosts. Eukaryot Cell 11:1313-1323

Geisen S, Koller R, Hünninghaus M et al (2015a) The soil food web revisited: diverse and widespread mycophagous soil protists. Soil Biol Biochem 94:10-18. https://doi.org/10. 1016/j.soilbio.2015.11.010

Geisen S, Lara E, Mitchell E, et al (2020) Soil protist life matters. Soil Organisms 92(3): 189-196. Soil Org 92:189-196. https://doi.org/10.25674/so92iss3pp189

Geisen S, Tveit AT, Clark IM et al (2015b) Metatranscriptomic census of active protists in soils. ISME J 9:2178-2190. https://doi.org/10.1038/ismej.2015.30

Glücksman E, Bell T, Griffiths RI, Bass D (2010) Closely related protist strains have different grazing impacts on natural bacterial communities. Environ Microbiol 12:3105-3113. https://doi.org/10.1111/j.1462-2920.2010. 02283.x

Grossmann L, Jensen M, Heider D et al (2016) Protistan community analysis: key findings of a large-scale molecular sampling. ISME J 10:2269-2279. https://doi.org/10.1038/ ismej. 2016.10

Guajardo J, Saa S, Riquelme N et al (2019) Characterization of oomycete species associated with root and crown rot of english walnut in chile. Plant Dis 103:691-696. https://doi. org/10.1094/PDIS-07-18-1160-RE

Guillou L, Bachar D, Audic S et al (2013) The Protist Ribosomal Reference database (PR2): a catalog of unicellular eukaryote Small Sub-Unit rRNA sequences with curated taxonomy. Nucleic Acids Res 41:597-604. https://doi.org/ 10.1093/nar/gks1160 
Hendrix PF, Bohlen PJ (2002) Exotic earthworm invasions in North America: ecological and policy implications. Bioscience 52:801-811

Hirakata Y, Hatamoto M, Oshiki M et al (2019) Temporal variation of eukaryotic community structures in UASB reactor treating domestic sewage as revealed by $18 \mathrm{~S}$ rRNA gene sequencing. Sci Rep 9:12783. https://doi.org/10. 1038/s41598-019-49290-y

Hittorf M, Letsch-Praxmarer S, Windegger A et al (2020) Revised Taxonomy and Expanded Biodiversity of the Phytomyxea (Rhizaria, Endomyxa). J Eukaryot Microbiol 67:648-659. https://doi.org/10.1111/jeu.12817

Holdsworth AR, Frelich LE, Reich PB (2007) Regional extent of an ecosystem engineer: earthworm invasion in northern hardwood forests. Ecol Appl 17:1666-1677. https://doi. org/10.1890/05-2003.1

Jauss R, Walden S, Fiore-Donno A et al (2020) From forest soil to the canopy: increased habitat diversity does not increase species richness of Cercozoa and Oomycota in tree canopies. Front Microbiol 11:592189. https://doi.org/10.3389/ fmicb.2020.592189

Jochum M, Ferlian O, Thakur MP et al (2021) Earthworm invasion causes declines across soil fauna size classes and biodiversity facets in northern North American forests. Oikos 130:766-780. https://doi.org/10.1111/oik.07867

Jung T, Hudler G, Jensen-Tracy S et al (2005) Involvement of phytophthora species in the decline of European beech in Europe and the USA. Mycologist 19:159-166. https://doi. org/10.1017/S0269-915X(05)00405-2

Knollenberg WG, Merritt RW, Lawson DL (1985) Consumption of leaf litter by lumbricus terrestris (Oligochaeta) on a michigan woodland floodplain. Am Midl Nat 113:1-6

Lavelle P, Bignell D, Lepage M et al (1997) Soil function in a changing world: the role of invertebrate ecosystem engineers. Eur J Soil Biol 33:159-193

Lentendu G, Wubet T, Chatzinotas A et al (2014) Effects of long-term differential fertilization on eukaryotic microbial communities in an arable soil: a multiple barcoding approach. Mol Ecol 23:3341-3355. https://doi.org/10. 1111/mec.12819

Maraun M, Alphei J, Bonkowski M et al (1999) Middens of the earthworm Lumbricus terrestris (Lumbricidae): microhabitats for micro- and mesofauna in forest soil. Pedobiologia (jena) 43:276-287

Moore JC, McCann K, De Ruiter PC (2005) Modeling trophic pathways, nutrient cycling, and dynamic stability in soils. In: Pedobiologia. Elsevier GmbH, pp 499-510

Nuzzo VA, Maerz JC, Blossey B (2009) Earthworm invasion as the driving force behind plant invasion and community change in Northeastern North American Forests. Conserv Biol 23:966-974. https://doi.org/10.1111/j.1523-1739. 2009.01168.x

Oksanen J, Blanchet FG, Kindt R, et al (2014) Vegan: community ecology package. R Package Version 2.2-0. http:// cran.rproject.org/package $=$ vegan

Öztoprak H, Walden S, Heger T et al (2020) What drives the diversity of the most abundant terrestrial cercozoan family (Rhogostomidae, cercozoa, rhizaria)? Microorganisms 8:1123. https://doi.org/10.3390/microorganisms8081123
Schaefer M, Schauermann J (1990) The soil fauna of beech forests: comparison between a mull and a moder soil. Pedobiologia (jena) 34:299-314

Scheu S (1987) The influence of earthworms (Lumbricidae) on the nitrogen dynamics in the soil litter system of a decidous forest. Oecologia 72:197-201

Scheu S (1994) There is an earthworm mobilizable nitrogen pool in soil. Pedobiologia (jena) 38:243-249

Scheu S, Setälä H (2002) Multitrophic interactions in decomposer food-webs. In: Tscharntke T, Hawkins B (eds) Multitrophic level interactions. Cambridge University Press, Cambridge

Scheu S, Wolters V (1991) Influence of fragmentation and bioturbation on the decomposition of 14C-labelled beech leaf litter. Soil Biol Biochem 23:1029-1034

Schlaghamerský J, Eisenhauer N, Frelich LE (2014) Earthworm invasion alters enchytraeid community composition and individual biomass in northern hardwood forests of North America. Appl Soil Ecol 83:159-169. https://doi.org/10. 1016/j.apsoil.2013.09.005

Schloss PD, Westcott SL, Ryabin T et al (2009) Introducing mothur: open-source, platform-independent, communitysupported software for describing and comparing microbial communities. Appl Environ Microbiol 75:7537-7541. https://doi.org/10.1128/AEM.01541-09

Schröter D, Wolters V, De Ruiter PC (2003) C and N mineralisation in the decomposer food webs of a European forest transect. Oikos 102:294-308. https://doi.org/10.1034/j. 1600-0579.2003.12064.x

Seppey CVW, Singer D, Fournier B et al (2017) Distribution patterns of soil microbial eukaryotes suggests widespread algivory by phagotrophic protists as an alternative pathway for nutrient cycling. Soil Biol Biochem 112:68-76. https:// doi.org/10.1016/j.soilbio.2017.05.002

Sibbald SJ, Archibald JM (2017) More protist genomes needed. Nat Publ Gr 1:1-3. https://doi.org/10.1038/s41559-0170145

Singer D, Kosakyan A, Seppey CVW et al (2018) Environmental filtering and phylogenetic clustering correlate with the distribution patterns of cryptic protist species. Ecology 99:904-914. https://doi.org/10.1002/ecy.2161

Singer D, Mitchell EAD, Payne RJ et al (2019) Dispersal limitations and historical factors determine the biogeography of specialized terrestrial protists. Mol Ecol 28:3089-3100. https://doi.org/10.1111/mec.15117

Straube D, Johnson EA, Parkinson D et al (2009) Nonlinearity of effects of invasive ecosystem engineers on abiotic soil properties and soil biota. Oikos 118:885-896. https://doi. org/10.1111/j.1600-0706.2009.17405.x

Tao J, Chen X, Liu M et al (2009) Soil Biology \& Biochemistry Earthworms change the abundance and community structure of nematodes and protozoa in a maize residue amended rice - wheat rotation agro-ecosystem. Soil Biol Biochem 41:898-904. https://doi.org/10.1016/j.soilbio.2008.12.002

Tedersoo L, Bahram M, Cajthaml T et al (2016) Tree diversity and species identity effects on soil fungi, protists and animals are context dependent. ISME J 10:346-362. https:// doi.org/10.1038/ismej.2015.116

Tiunov AV, Bonkowski M, Alphei J, Scheu S (2001) Microflora protozoa and nematoda in lumbricus terrestris burrow walls: a laboratory experiment. Pedobiologia 60:46-60 
Trap J, Bonkowski M, Plassard C et al (2016) Ecological importance of soil bacterivores for ecosystem functions. Plant Soil 398:1-24. https://doi.org/10.1007/s11104-0152671-6

Urich T, Lanzén A, Qi J et al (2008) Simultaneous assessment of soil microbial community structure and function through analysis of the meta-transcriptome. PLoS ONE 3:e2527. https://doi.org/10.1371/journal.pone.0002527

Vargas LIR, Negron-Ortiz V (2013) Root and soil-borne Oomycetes (Heterokontophyta) and fungi associated with the endangered conifer, Torreya taxifolia Arn. (Taxaceae) in Georgia and Florida, USA. Life Excit Biol 1:202-223. https://doi.org/10.9784/LEB1(4)RiveraVargas.03

Venter PC, Nitsche F, Domonell A et al (2017) The protistan microbiome of grassland soil: diversity in the mesoscale.
Protist 168:546-564. https://doi.org/10.1016/j.protis.2017. 03.005

Voss C, Fiore-Donno AM, Guerreiro MA et al (2019) Metatranscriptomics reveals unsuspected protistan diversity in leaf litter across temperate beech forests, with Amoebozoa the dominating lineage. FEMS Microbiol Ecol. https://doi. org/10.1093/femsec/fiz142

Weber AA-T, Pawlowski J (2013) Can abundance of protists be inferred from sequence data: a case study of foraminifera. PLoS ONE 8:e56739

Publisher's Note Springer Nature remains neutral with regard to jurisdictional claims in published maps and institutional affiliations. 